\title{
Archives génétiques de littérature pour la jeunesse
}

\section{Christine Collière-Whiteside}

\section{OpenEdition}

\section{Journals}

Édition électronique

URL : http://journals.openedition.org/genesis/4171

DOI : 10.4000/genesis.4171

ISSN : 2268-1590

\section{Éditeur :}

Presses universitaires de Paris Sorbonne (PUPS), Société internationale de génétique artistique littéraire et scientifique (SIGALES)

\section{Édition imprimée}

Date de publication : 1 juin 2019

Pagination : 145-146

ISSN : 1167-5101

\section{Référence électronique}

Christine Collière-Whiteside, "Archives génétiques de littérature pour la jeunesse », Genesis [En ligne], 48 | 2019, mis en ligne le 01 juin 2020, consulté le 25 janvier 2021. URL : http://

journals.openedition.org/genesis/4171; DOI : https://doi.org/10.4000/genesis.4171 


\title{
Archives génétiques de littérature pour la jeunesse
}

\author{
Christine Collière-Whiteside
}

$\mathrm{N}$ ous avons choisi de présenter ici trois fonds consacrés exclusivement à la littérature jeunesse, qui regroupent des archives de nombreux, voire de très nombreux auteurs, illustrateurs ou auteurs-illustrateurs pour la jeunesse : les archives de Seven Stories à Newcastle au Royaume-Uni, la Kerlan Collection à l'université du Minnesota et le Centre de l'illustration de la médiathèque André Malraux à Strasbourg.

Ce ne sont bien entendu pas les seuls fonds concernant la littérature pour la jeunesse. La De Grummond Collection 1 , par exemple, à l'université du Southern Mississippi, rassemble des manuscrits originaux et des illustrations de plus de 1300 auteurs et illustrateurs ainsi que des œuvres publiées de 1530 à nos jours. D'autres fonds ou des documents isolés appartenant à la littérature jeunesse sont conservés au sein d'institutions plus générales. Ainsi, on trouve des avant-textes de Babar aussi bien à la BnF qu'à la Morgan Library \& Museum à New York ${ }^{2}$, où se trouve également le manuscrit du Petit Prince de Saint-Exupéry ${ }^{3}$. In fine, c'est le choix de la collection ou de la maison d'édition qui définit une œuvre comme appartenant ou non à la littérature pour la jeunesse. On notera la présence à l'IMEC d'un grand nombre de fonds de maisons d'éditions spécialisées, qui apportent un éclairage indispensable : y sont représentées les maisons Hachette, Nathan, Bias, Gautier-Languereau, Hetzel, Flammarion, Froissart, À l'enfant poète, les éditions du Rouergue, Paul Hartmann, Pierre Lafitte ou Tallandier. Par ailleurs, l'IMEC conserve les archives d'un certain nombre d'auteurs qui ont écrit pour la jeunesse : Marcel Aymé, Agnès Rosenstiehl, Boileau-Narcejac, Fred Kupferman, Claude Pujade-Renaud et Daniel Zimmermann, Charles Vildrac ou Abdellatif Laâbi ont ainsi attiré notre attention, mais la liste n'est sans doute pas exhaustive. Enfin, on pourra citer quelques archives consacrées à des auteurs uniques, comme celles de Roald Dahl à Great Missenden, l'institut René Goscinny à Paris ${ }^{4}$, les manuscrits du musée Jules Verne à Nantes 5 ou les archives Henri Bosco, déposées à la faculté des lettres de l'université de Nice, qui rassemblent tous ses papiers, manuscrits, brouillons, correspondances, carnets, ainsi que sa bibliothèque 6 .

La littérature pour la jeunesse se caractérise par une forte présence d'iconotextes en tout genre. Les fonds déposés à la Cité internationale de la bande dessinée et de l'image à Angoulême concernent en partie la littérature pour la jeunesse et ont été présentés dans un entretien avec JeanPierre Mercier dans le numéro 43 de Genesis sur la BD 7 . Le Musée de l'illustration jeunesse à Moulins ${ }^{8}$ rassemble pour sa part essentiellement des œuvres originales mais aussi des esquisses et des documents de travail. Le musée Tomi

1. https://www.degrummond.org, consulté le 18 juin 2018.

2. Voir, par exemple, Christine Nelson, Drawing Babar : Early drafts and watercolours, New York, The Morgan Library \& Museum, 2008 et Isabelle Nières-Chevrel, Au pays de Babar: les albums de Jean de Brunhoff, Rennes, PUR, 2017.

3. Le Manuscrit du «Petit Prince» d'Antoine de Saint-Exupéry : facsimilé et transcription, A. Cerisier et D. Lacroix (dir.), Paris, Gallimard, 2013. Il a fait l'objet d'une exposition intitulée «The Little Prince : a New York Story » en 2014 à New York.

4. https://www.institut-goscinny.org/, consulté le 15 février 2018.

5. Voir William Butcher, Jules Verne inédit : les manuscrits déchiffrés, Lyon, ENS éditions 2015.

6. http://bibliotheque.unice.fr/ressources/presentation-des-ressources/ les-collections-remarquables/collection-henri-bosco/archives-henribosco, consulté le 13 mai 2018.

7. Luc Vigier, «Planches originales : préserver, restaurer, lire», Genesis, $n^{\circ} 43$ «Bande Dessinée», 2016, p. 147-155.

8. Voir notamment la page «Archives» sur le site du musée, où sont rassemblés les dossiers de presse et les dossiers pédagogiques des expositions : http://musees.allier.fr/434-archives.htm 
Ungerer, à Strasbourg, abrite un fonds important d'œuvres graphiques et d'archives documentaires données par l'artiste à sa ville natale, ainsi que sa collection personnelle de jouets, qui ont joué une fonction génétique essentielle dans son œuvre $^{9}$, et expose également d'autres artistes. De même, le musée The House of Illustration à Londres, ouvert en 2014, est le fruit d'un projet qui a commencé en 2002 lorsque Quentin Blake a fait don de ses archives (4000 dessins originaux et 250 livres illustrés), et qui s'est poursuivi par une série d'expositions itinérantes : «Fifty years of Quentin Blake» en 2004, «In all directions » en 2006, «What are you like? en 2008, ou encore «Picture it», un programme éducatif, en 200910.
S'il est évidemment impossible d'établir une liste exhaustive des institutions conservant des documents génétiques relatifs à la littérature pour la jeunesse, l'existence d'institutions spécialisées atteste de la relation particulière que le public de tous âges entretient avec ces œuvres.

9. Évelyne Bedoin, «La collection de jouets Tomi Ungerer, une archive de l'œuvre?», dans Littérature de jeunesse : la fabrique de la fiction, P. Clermont et D. Henky (dir.), Francfort-sur-Main, Peter Lang Édition, 2017, 61-78

10. https://www.houseofillustration.org.uk 